\title{
Analysis of the work rates and heart rates of association football referees
}

\author{
C. Catterall Dip HE, T. Reilly PhD, G. Atkinson BSc(Hons), A. Coldwells BSc(Hons) \\ Centre for Sport and Exercise Sciences, School of Human Sciences, Liverpool John Moores University, Liverpool, \\ UK
}

\begin{abstract}
This study aimed to describe the work-rate profiles of referees during soccer matches and record heart-rate responses during these games. Using video-recordings 14 referees were observed and their heart rates during the games were monitored by short-range radio telemetry. These included 11 football league matches. The exercise intensity was largely submaximal with a change in activity every $6 \mathrm{~s}$. The mean distance covered during the game was $9.44 \mathrm{~km}$; a significant fall in work rate was noted in the second half $(P<0.05)$. The mean heart rate of 165 beats $\min ^{-1}$ did not vary between first and second halves. The work rate and heart rate varied more between individuals than with the importance of the match, but this variation was small. It was considered that refereeing top level soccer places high physiological demands on the official. This has implications for training and fitness assessment.
\end{abstract}

Keywords: Physiological strain, soccer, refereeing, distance covered

The studies reported in the literature on the physiological demands of soccer are almost exclusively concerned with players. The work rate and activity profiles have been employed as gross measures of the demands of the game ${ }^{1}$. The heart-rate responses to play have been used also as indices of physiological strain ${ }^{2}$. While heart rate is not altogether convenient for monitoring players' responses to top-level play because of the physical contact involved, it is convenient for monitoring referees' responses.

Soccer referees at the top level tend to occupy an older age range than the players, in view of the need to have experience before becoming eligible for officiating in the Football League's matches. Referees differ from players also in that they are not professionals, generally holding full-time employment outside the game. Nevertheless they are expected to keep up with play, whatever its tempo, and maintain alertness throughout the game. The fitness required to do this depends on the demands of the game. This study was concerned with outlining

Address for correspondence: Professor Thomas Reilly, School of Human Sciences, Liverpool John Moores University, Byrom Street, Liverpool L3 3AF, UK

(C) 1993 Butterworth-Heinemann Ltd

0306-3674/93/030193-04 the work-rate demands of refereeing top-level soccer matches and monitoring physiological responses of referees during matches.

\section{Subjects and methods}

Subjects $(n=14)$ were all experienced class 1 referees who either refereed at the highest league or non-league level. Verbal consent was obtained from all subjects before the study, following brief explanations as to the nature of the investigation. Consent of the home club was sought for admittance to the referee's dressing room before kick-off and after the game. The referees were examined during the second half of the 1991-1992 competitive season. The categories of games monitored were: four first division football league (now premier league) matches; two second division football league (now first division) matches; four third division football league (now second division) matches; two Vauxhall Conference League matches; and two HFS Loans League matches.

\section{Work-rate evaluation}

In order to estimate the distance that a referee covered during the $90 \mathrm{~min}$ of play, each game was video-recorded using a camcorder. The film was obtained from a position in the main stand overlooking the pitch and close to the half-way line. The camera operator followed the referee's movements in the view finder for the duration of the game.

In determining the distance covered four levels of exercise intensity were categorized. These were sprinting, jogging, walking and reverse running. Each individual referee's stride lengths were calculated by monitoring his movement directly across the centre circle. Once the stride length for each type of action (walking, jogging, sprinting and reverse running) had been calculated, it was then possible to estimate the distance covered during the game for each particular action. This was performed by counting the total number of walking, jogging, sprinting and reverse running strides that the referee took during the game and multiplying these by the appropriate stride lengths. The frequencies of each action were recorded in 45-min periods in order to compare the two halves. This method of estimating distance covered during a game and of establishing 
work-rate profiles for football players has been used in previous investigations ${ }^{3,4}$ and proved to be highly reliable ${ }^{3}$.

\section{Heart rate monitoring}

The heart rate was used as an indication of the cardiovascular strain imposed on referees during matches. Thus any relations between the work rate and the heart rate could be determined.

Heart rate was recorded for the full duration of each game by means of short-range radio telemetry (Polar Electro, Kempele, Finland). A chest monitor transmits the heart-rate signal to a receiver worn on the wrist. The heart rate was recorded every $5 \mathrm{~s}$. The data stored in the watch were down-loaded on to a personal computer for analysis following the game. A graphical example of the computer print-out is given in Figure 1.

The heart-rate monitor was placed on the referee approximately $30 \mathrm{~min}$ before kick-off. This allowed the subject to become familiar with the equipment. It was removed from the subject about $10 \mathrm{~min}$ after the game ended.

\section{Statistical analyses}

Mean values for work rates in each half were compared using Student's $t$ tests. The alpha level of significance was determined as $5 \%(P<0.05)$. Maximal heart rates were estimated using the formula 220 - age ${ }^{5}$. Work rates were calculated as a percentage of these maxima. Relations between work rate (distance covered) and cardiovascular strain (mean heart rate) were examined with Pearson's correlation coefficient.

\section{Results}

\section{Work rate}

The distances covered over the period of a whole match $(90 \mathrm{~min}$ ) ranged from $7977 \mathrm{~m}$ to $10187 \mathrm{~m}$ (Table 1). Mean values for each half were compared

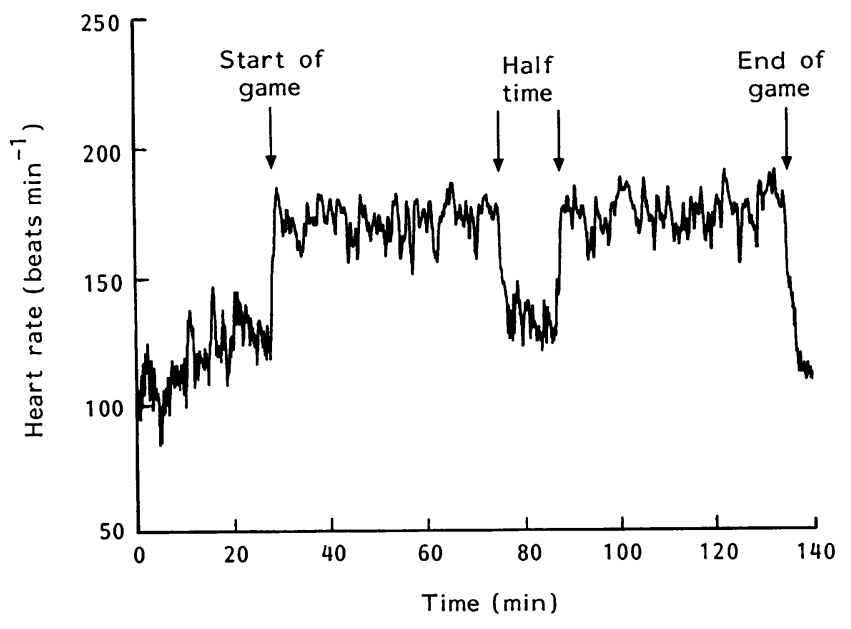

Figure 1. An example of the graphical output of the heart-rate recordings. The figure shows the heart rate versus time
Table 1. Total distance $(m)$ covered by each referee

\begin{tabular}{lllc}
\hline Subject & First half & Second half & Total \\
\hline 1 & 5488 & 4132 & 9620 \\
2 & 4951 & 4920 & 9871 \\
3 & 4954 & 4860 & 9814 \\
4 & 5329 & 4858 & 10187 \\
5 & 4409 & 4431 & 8840 \\
6 & 5103 & 5069 & 10172 \\
7 & 5031 & 4543 & 9574 \\
8 & 4231 & 3746 & 7977 \\
9 & 5150 & 4791 & 9941 \\
10 & 5287 & 4697 & 9984 \\
11 & 4884 & 4476 & 9360 \\
12 & 4551 & 4517 & 9068 \\
13 & 4025 & 4256 & 8281 \\
Mean(s.d.) & $4876(445)$ & $4561(366)$ & $9438(707)$ \\
\hline
\end{tabular}

statistically using a Student's $t$ test on 13 subjects (one referee sustained an injury in the first half and was replaced at half-time). Significantly less distance was covered by the referees in the second half compared to the first half $(P<0.05)$. This amounted to a decrement of over $400 \mathrm{~m}$ in six of the 13 referees that were studied.

A breakdown of the distances covered in each of the activity categories is provided in Table 2 . These results indicate that the majority of the game was

Table 2. Distance covered $(m)$ for each activity in the games studied*

\begin{tabular}{lllll}
\hline Subject & \multicolumn{3}{c}{ Activity } \\
\cline { 2 - 5 } & Walking & Jogging & Sprinting & Reverse running \\
\hline & & & & \\
1 & 1465 & 5407 & 833 & 1915 \\
& $(15.2)$ & $(56.2)$ & $(8.7)$ & $(19.9)$ \\
2 & 2106 & 4429 & 1429 & 1907 \\
3 & $(21.3)$ & $(44.9)$ & $(14.5)$ & $(19.3)$ \\
& 3211 & 3979 & 1232 & 1392 \\
4 & $(32.7)$ & $(40.5)$ & $(12.6)$ & $(14.2)$ \\
& 2018 & 5118 & 970 & 2081 \\
5 & $(19.8)$ & $(50.2)$ & $(9.5)$ & $(20.5)$ \\
& 3073 & 3996 & 675 & 1096 \\
6 & $(34.8)$ & $(45.2)$ & $(7.6)$ & $(12.4)$ \\
& 2526 & 4941 & 1163 & 1542 \\
7 & $(24.8)$ & $(48.6)$ & $(11.4)$ & $(15.2)$ \\
& 1981 & 5200 & 960 & 1433 \\
8 & $(20.7)$ & $(54.3)$ & $(10.0)$ & $(15.0)$ \\
& 1413 & 3640 & 1772 & 1152 \\
9 & $(17.7)$ & $(45.6)$ & $(22.2)$ & $(14.5)$ \\
10 & 1888 & 4864 & 2058 & 1131 \\
& $(19.0)$ & $(48.9)$ & $(20.7)$ & $(11.4)$ \\
11 & 2132 & 4519 & 730 & 2603 \\
& $(21.4)$ & $(45.3)$ & $(7.3)$ & $(26.1)$ \\
12 & 1900 & 3505 & 936 & 3019 \\
& $(20.3)$ & $(37.4)$ & $(10.0)$ & $(32.3)$ \\
13 & 2291 & 4222 & 790 & 1765 \\
& $(25.3)$ & $(46.5)$ & $(8.7)$ & $(19.5)$ \\
Mean(s.d.) & 2114 & 3957 & 863 & 1347 \\
& $(25.5)$ & $(47.8)$ & $(10.4)$ & $(16.3)$ \\
& $2163(527)$ & $4444(620)$ & $1109(419)$ & $1722(584)$ \\
& $(23.0)$ & $(47.0)$ & $(11.8)$ & $(18.2)$ \\
\hline
\end{tabular}

The distance covered in each mode expressed as a percentage of the total distance is given in parentheses 
spent jogging with walking being the next main activity. A considerable distance $(1722 \mathrm{~m})$ was covered running backwards, with sprinting being the least common activity among the referees.

\section{Heart rate}

Resting heart rates before kick-off were high, approaching 100 beats $\min ^{-1}$. An example of the heart-rate recordings for one subject is shown in Figure 1. The mean(s.d.) heart rate for all the referees over the duration of a full game was 165(8) beats $\min ^{-1}$. This corresponds to approximately $95 \%$ of the referees' estimated maximal heart rate. The highest peak heart rates were incurred in the top division matches and reached 200 beats $\min ^{-1}$ in some instances. The mean heart rate was unaffected by the category of competition. No significant correlation $(r$ $=0.15 ; P>0.05$ ) was found between the mean heart rate and the distance covered during a game, indicating the individual variations in the responses.

There was no significant difference $(P<0.05)$ between the heart rates recorded in the first and second halves (Table 3 ). This was despite the reduced work rate (as measured by distance covered) in the second half.

\section{Discussion}

Motion analysis can give a useful pointer to the physiological demands imposed by activity. This is based on the essentially direct relationship between energy expenditure and distance covered in a game. The results of this study suggest that referees cover a distance of almost $9.5 \mathrm{~km}$ over the duration of an élite-level football match. This compares to the mean values of $10.5 \mathrm{~km}$ for seven foreign referees at international matches in Japan and $11.18 \mathrm{~km}$ for ten Japanese referees of the Japan National Soccer League matches ${ }^{6}$. These distances are comparable with work rates reported for midfield soccer players and may be greater than the distances covered by some players, notably defenders ${ }^{1}$.

The overall pattern of a referee's activity was acyclical but varied in parallel with the players'

Table 3. Mean heart rates (beats $\mathrm{min}^{-1}$ ) in the first and second halves of the game

\begin{tabular}{lll}
\hline Subject & First half & Second half \\
\hline 1 & 152 & 152 \\
2 & 171 & 174 \\
3 & 172 & 175 \\
4 & 173 & 174 \\
5 & 171 & 157 \\
6 & 172 & 174 \\
7 & 152 & 154 \\
8 & 172 & 175 \\
9 & 157 & 159 \\
10 & 165 & 165 \\
11 & 169 & 172 \\
12 & 159 & 159 \\
13 & 156 & 155 \\
Mean(s.d.) & $165(8)$ & $165(9)$ \\
\hline
\end{tabular}

actions. For example, although the majority of distance was covered by sustained submaximal exercise (jogging, walking, running backwards), approximately $1.1 \mathrm{~km}$ was covered in sprints. Therefore, a wide range of physiological attributes is required of the referee including high values of both aerobic and anaerobic capacities to meet the demands of officiating a match. These findings support the adoption of specialized intensive training regimens by referees. These regimens should place emphasis on aerobic stimuli in view of the necessity to maintain a high work rate throughout the game.

The drop in the referee's work rate in the second half of a game has also been shown for football players $^{3}$. This is thought to result from fatigue linked to diminished energy stores within the active muscles $^{7}$. In the present study, however, it was unclear whether the reduced work rate of the referees in the second half was a consequence of fatigue or merely an artefact of the reduced work rate of the players. If the former is true, the second half decrement may be reduced by increasing fitness and adopting a carbohydrate loading diet, in the 3 days preceding the match. Previously, Brodie $(1981)^{8}$ reported no difference in work rates of soccer referees between first and second halves, although the distance covered was only about $60 \%$ of that noted in the present sample.

Heart rate is a useful index of the physiological strain incurred by physical activity. Heart rate increases in order to facilitate the transport of oxygen to the working muscles. However, heart rate can also be affected by stress mediated by the secretion of the 'stress hormones' such as adrenaline and noradrenaline. The psychological component of heart rate is illustrated by the fact that pre-match heart rates were as high as 100 beats $\min ^{-1}$; this could not be attributed solely to anxiety as referees tended to engage in light warm-up activity in the dressing rooms. It is also of interest to note that even the experienced referees that comprised the present sample displayed tachycardia before a game. The psychological influence on heart rate tends to disappear during strenuous physical exercise ${ }^{5}$ and, in the present study, the heart rate was relatively stable during the matches.

Although work rate was lower in the second compared to the first half of a game, the high heart rates were maintained in the second period. There is an increase in heart rate during sustained exercise due to 'cardiovascular drift' ${ }^{5}$. The high heart rates may also be explained by a rise in body temperature as the match progresses. The relative stability in heart rate throughout the game may reflect the ability of referees to pace their efforts over $90 \mathrm{~min}$ of activity according to the level of physiological strain. This compares with observations on soccer players of 169 beats $\min ^{-1}$ and 165 beats $\min ^{-1}$ for first and second halves respectively in Belgian university players ${ }^{9}$.

The relative physiological strain on the referees may be overestimated by the figure of $95 \% \mathrm{HR}_{\max }$. The formula utilizing the age-correction on the estimated maximal heart rate may exaggerate the ageing effect on this function ${ }^{10}$; nevertheless, the mean heart rates throughout the game represent 
values similar to those observed in players. The referees at this level of competition are on average about 15 years older than professional players and the physiological demands of refereeing must therefore be deemed appreciable. While players incur additional energy expenditure when directly involved in executing match skills, they have a degree of choice in undertaking high intensity efforts 'off-the-ball'. By contrast, the referee is obliged to follow the play, irrespective of the intensity of his previous movements. While the referee does not display the acute-angled changes of direction observed among players, the overall work-rate profiles and the frequency of discrete events (a change in category of activity every $6 \mathrm{~s}$ ) are similar.

In conclusion, it seems that the major physiological demands on referees are imposed on the oxygen transport system. Superimposed on these demands are short periods of high intensity effort. The next step is to assess the fitness levels of contemporary referees for meeting these demands and to prescribe appropriate training regimens for referees at the top level.

\section{Acknowledgements}

The authors acknowledge the staff of the Referees Association for their support in this project. The assistance of the management of the following clubs was also greatly appreciated: Everton FC,
Liverpool FC, Manchester United, Middlesbrough FC, Oldham FC, Preston NE, Stoke FC, Tranmere Rovers FC and Wigan FC. The cooperation of officials of the Vauxhall Conference and HFS Loans Leagues was invaluable.

\section{References}

1 Reilly T. Football. In: Reilly T, Secher N, Snell P, Williams C, eds. Physiology of Sports. London, UK: E and FN Spon, 1990: 371-425.

2 Reilly T, Clarys JP, Stibbe A. Science and Football II. London, UK: E and FN Spon, 1993.

3 Reilly T, Thomas V. A motion analysis of work-rate in different positional roles in professional football match play. Journal of Human Movement Studies 1976; 2: 87-97.

4 Bangsbo J, Norregaard L, Thorso F. Activity profile of competitive soccer. Can J Appl Sports Sci 1991; 16: 110-16.

5 Astrand PO, Rodahl K. Textbook of Work Physiology. New York, USA: McGraw-Hill, 1977.

6 Asami $T$, Togari $H$, Ohashi J. Analysis of movement patterns of referees during soccer matches. In: Reilly $\mathrm{T}$, Lees A, Davids K, Murphy WJ, eds. Science and Football. London, UK: E and FN Spon, 1988: 341-5.

7 Saltin B. Metabolic fundamentals in exercise. Med Sci Sports 1973; 5: 137-46.

8 Brodie D. A movement analysis of association football referees. Report to the Football League, 1981.

9 Van Gool D, Van Gerven D, Boutmans J. The physiological load imposed on soccer players during real match play. In: Reilly T, Lees A, Davids K, Murphy WJ, eds. Science and Football. London, UK: E and FN Spon, 1988: 51-9.

10 Shephard R. Physical Activity and Ageing. London, UK: Croom Helm, 1987.

\section{BASM Merchandise}

\begin{tabular}{|c|c|c|}
\hline Ladies scarves & $\begin{array}{l}\text { White with blue border and BASM logo }-27 \text {-inch square } \\
\text { Navy blue with fringe and BASM logo } 54 \times 9 \text { inches (oblong) }\end{array}$ & $\begin{array}{l}£ 5+£ 1 p \& p \\
£ 5+£ 1 p \& p\end{array}$ \\
\hline Sweatshirts & White with large motif: medium $36-38$ inches; large $40-42$ inches; extra large 44 inches & $£ 10+£ 1 p \& p$ \\
\hline Tee shirts & Light blue with large motif: medium $36-38$ inches; large $40-42$ inches; extra large 44 inches & $£ 6+£ 1 p \& p$ \\
\hline Ties & $\begin{array}{l}\text { Single motif } \\
\text { Multi motif }\end{array}$ & $£ 6+£ 1 p \& p$ \\
\hline Blazer badge & $\begin{array}{l}\text { Wire }-4 \text { inches high } \\
\text { Wire }-3 \text { inches high }\end{array}$ & $£ 5+£ 1 p \& p$ \\
\hline \multicolumn{3}{|l|}{ New stock to order } \\
\hline Track/leisure suits & $\begin{array}{r}\text { Umbro, with small motif to order: ladies: } 10,12,14,16 \\
\text { gents: } S, M, L, X L\end{array}$ & Quotes \\
\hline Sweaters & $\begin{array}{l}\text { Lambswool fine knit vee neck or round neck with small motif; machine washable } \\
\text { Colours and chest size to order }\end{array}$ & $£ 32+£ 1 p \& p$ \\
\hline Slipovers & $\begin{array}{l}\text { Fine knit lambswool vee neck or round neck with small motif; } \\
\text { machine washable }\end{array}$ & $£ 30+£ 1 p \& p$ \\
\hline Dress shirts & $\begin{array}{l}\text { White short sleeve, small motif } \\
\text { Collar size to order }\end{array}$ & $£ 18+£ 1 p \& p$ \\
\hline Sweatshirts & $\begin{array}{l}\text { Small motif } \\
\text { Colours and chest size to order }\end{array}$ & $£ 20+£ 1 p \& p$ \\
\hline Polo shirts & $\begin{array}{l}\text { Small motif } \\
\text { Colours and chest size to order }\end{array}$ & $£ 18+£ 1 p \& p$ \\
\hline Umbrellas & With motif to order & $£ 18+£ 2 p \& p$ \\
\hline
\end{tabular}

For further details please contact: John $\mathrm{H}$. Clegg JP LDS RCS Eng, National Sales Officer, Birch Lea, 67 Springfield Lane, Eccleston, St. Helens, Merseyside WA10 5HB, UK. (Tel: 0744 28198) 